\title{
A DIVISÃO SEXUAL DO TRABALHO E OS IMPACTOS DO DESENVOLVIMENTO TECNOLÓGICO
}

\section{The Sexual Division Of Work And The Impacts Of Technological DevelopmenT}

Raquel Quirino ${ }^{34}$

\section{Resumo}

Este Artigo apresenta uma discussão acerca da tecnologia e da divisão sexual do trabalho. Aborda a conceituação da tecnologia, a partir das suas inovações, e questiona o requerimento de diferentes qualificações e competências para o trabalhado masculino e o feminino. Há no sistema produtivo tarefas e funções diferenciadas quando se tem diferentes tipos de máquinas, caracterizando uma autêntica divisão sexual do trabalho, seja no chão de fábrica, seja nos setores de gestão e desenvolvimento de produtos. Tarefas rotineiras e repetitivas são designadas para a mulher, enquanto funções de valor tecnológico agregado são de responsabilidade do homem. Apesar dos avanços tecnológicos e da democratização no mundo do trabalho, ainda não se tem uma igualdade na distribuição das atividades produtivas, seja quanto à tecnologia física ou a de gestão, relativas à atuação do homem e da mulher no mundo do trabalho.

Palavras-chave: Desenvolvimento tecnológico; Divisão sexual do trabalho; Trabalho da mulher; Mundo do trabalho.

\section{Abstract}

This article presents a discussion of the technology and the sexual division of work. Addresses the conceptualization of technology, from their innovations, and questions the application of different skills and competencies for working male and female. There are tasks in the production system and differentiated functions when you have different types of machines, featuring 
an authentic sexual division of labor, whether on the factory floor, is in the areas of management and product development. Routine and repetitive tasks are assigned to the woman, while technological value-added functions are the responsibility of man. Despite technological progress and democratization in the workplace, there is still no equality in the distribution of productive activities, whether on the physical technology or management, relating to the role of man and woman in the working world.

Keywords: Technological development; Sexual division of work; Woman work; World of Work.

\section{Introdução}

Para Álvaro Vieira Pinto (2005, p. 219-220), a palavra "tecnologia" tem sido usada a todo momento, por pessoas das mais diversas qualificações e com propósitos divergentes. $\mathrm{O}$ autor classifica quatro significados principais para o tema:

- Tecnologia como a teoria, a ciência, o estudo, a discussão da técnica. As artes, as habilidades do fazer, as profissões, os modos de produzir alguma coisa, "logos da técnica";

- Tecnologia como pura e simplesmente a técnica, o know how;

- Tecnologia entendida como o conjunto de todas as técnicas de que dispõe uma determinada sociedade, em qualquer fase da história do desenvolvimento;

- Tecnologia como ideologização da técnica, ou seja, "(...) condensadamente, pode dize-se que neste caso a palavra tecnologia menciona a ideologia da técnica".

Por sua vez, Corrêa (1997, p. 250) define, genericamente, tecnologia "como um conjunto de conhecimentos e informações organizados, provenientes de fontes diversas como descobertas científicas e invenções, obtidos através de diferentes métodos e utilizados na produção de bens e serviços". Porém, alerta que, como toda produção humana, a tecnologia deve ser pensada no contexto das relações sociais e dentro de seu desenvolvimento histórico.

Laudares (2010) esclarece que embora, inicialmente a tecnologia tenha se constituído, na sua estrutura com o empirismo, hoje, tem base científica, e é uma construção multidisciplinar. Para ao autor o construto da tecnologia 
é desenvolvido pela trajetória da "energia" - como propulsora e força de ativação; "da ferramenta e da máquina" - como instrumento da produção técnica, e "da organização e gestão do processo produtivo" - tendo como agentes e principais atores da projeção e execução técnica, o/a trabalhador/a na sua atividade de trabalho.

Partindo da perspectiva da tecnologia como aplicação sistemática de conhecimentos científicos a fim de se alcançar, de maneira eficiente, determinados resultados práticos em várias esferas da vida, Gallino (1995) estabelece uma diferenciação entre os meios materiais (máquinas) e imateriais da tecnologia (processos e modelos).

Para Faria (1992) não é apenas o seu conteúdo ou natureza que define uma tecnologia como pertencente a uma classe ou categoria, mas também seu uso, sua inserção em um dado processo. Para o autor, a tecnologia de processo abrange as técnicas e o uso de técnicas que interferem no processo de trabalho/produção, de maneira a organizá-lo, sejam tais técnicas de ordem física ou de origem gerencial (tecnologia de gestão). Para este autor, temos:

- Tecnologia Física: compreendida pelas técnicas simples como ferramentas, máquinas mecânicas, mecanismos de controle de tempo e, também, técnicas sofisticadas, tais como robôs industriais e sistemas programáveis de controle de processos, automação, entre outras;

- Tecnologia de Gestão: conjunto de técnicas, instrumentos ou estratégias utilizadas pelos gestores para controlar o processo de produção em geral e de trabalho em particular, de maneira a otimizar os recursos nele empregados pondo em movimento a força de trabalho capaz de promover a geração de excedentes apropriáveis de forma privada ou coletiva (social).

Ainda segundo Faria (1992), a tecnologia física, por ser tangível é mais evidenciada e simples de se perceber como resultado da técnica. Porém a tecnologia de gestão contém inúmeras técnicas, desde aquelas de ordem instrumental, tais como técnicas/estratégica de racionalização do trabalho, estudo de tempo e movimento, disposição racional de máquinas, equipamentos na unidade produtiva, até técnicas de ordem comportamental e ideológica, que têm por finalidade introjetar, nos trabalhadores e trabalhadoras, valores fundamentais básicos ao desenvolvimento de tarefas, de acordo com o ponto de vista da ética capitalista. Exemplos dessas técnicas são os círculos de controle de qualidade, kanban, just in time entre outros. 
Para Corrêa (1997) de forma geral, a aplicação de tecnologias nas diferentes sociedades tem trazido impactos e consequências a inúmeros setores e também às relações sociais: à organização do trabalho e organização geral das empresas, à estrutura profissional e ao emprego, à privacidade individual, aos direitos do cidadão, às instituições políticas, ao modo de governar, à condução da guerra, aos costumes, às culturas, à família, à mobilidade geográfica da população, ao ambiente natural, à saúde e sobre as relações de gênero.

Considerando a tecnologia como a capacidade humana de perceber, compreender, criar, adaptar, organizar e produzir insumos, produtos e serviços, Bastos (1998) transcende a dimensão puramente técnica e incorpora outros elementos da vida social na tecnologia, o que a torna um vetor de expressão da cultura das sociedades.

Assim, Carvalho (2003, p. 21) considera

a compreensão da tecnologia como uma dimensão sociocultural na qual ela é gestada, permite considerá-la como um elemento fundante da sociedade, mas não determinante. A tecnologia é parte da cultura e deve ser compreendida em sua interconexão com outros elementos culturais. (CARVALHO, 2003, p. 21)

Para Figueiredo (1989) é importante ter-se presente o caráter social da tecnologia e sua característica de processo socialmente condicionado e também, por sua vez, condicionante. A tecnologia será sempre um resultado complexo de escolhas efetuadas por sujeitos sociais em situações concretas.

As formas e tipos de desenvolvimento capitalista em cada sociedade, as necessidades sociais e econômicas expressas como interesses e a correlação de forças existente irão influenciar o próprio nível de desenvolvimento tecnológico e suas formas, assim como seu impacto sobre a sociedade em questão. (CORRÊA, 1997, p. 256)

Outrossim, como a tecnologia e as relações de gênero estão imbricadas no mundo do trabalho - com suas divisões - e são também construtos sociais e culturais, é imprescindível verificar o impacto de uma sobre a outra em seu sentido mais amplo. 


\section{As inovações tecnológicas e o trabalho da mulher}

O desenvolvimento das técnicas produtivas, segundo Carvalho (2003), foi dominado pelos homens, em função da distribuição de papéis entre homens e mulheres na constituição da sociedade industrial, ficando as mulheres ausentes, pelo menos nas representações sociais, das atividades que produzem inovações tecnológicas.

Tendo em vista que as mulheres são também sujeitos sociais e considerando que a tecnologia é produzida dentro de uma sociedade específica, vinculada a outras relações sociais e à cultura, certamente as mulheres tiveram, e continuam tendo, participação na produção, apropriação e utilização das técnicas.

Como as alternativas aos modelos produtivos tayloristas ou fordistas, designados, por "especialização flexível", "novo conceito de produção", "neotaylorismo" ou ainda "pós-fordismo", são raramente conjugados no feminino, e na realidade generalizam ao conjunto da força de trabalho as transformações tecnológicas no universo produtivo concernente essencialmente aos homens, a inclusão da categoria relações de gênero em estudos que tratam de tecnologia permitem entender uma dimensão que esteve por muito tempo oculta nas abordagens sobre o tema.

Para Hirata (2002) na maior parte das vezes, as mulheres são ausentes enquanto atores sociais e o são também quando se trata de abordar o tema "tecnologia e divisão do trabalho". Para a autora, estudos sobre o trabalho e o "determinismo tecnológico", raramente fazem referência às consequências da tecnologia sobre o emprego e sobre o trabalho de acordo com os sexos. A autora questiona, de que maneira as novas tecnologias físicas e de gestão afetam a organização do trabalho, os postos e a qualificação para o trabalho e dos/as trabalhadores/as se a mão de obra for masculina ou feminina.

Citando o trabalho do grupo de pesquisa Sex and Class da CSE, a autora afirma:

O controle masculino da tecnologia desqualifica as mulheres da mesma maneira que os técnicos e os cientistas do capital desqualificam os operários. Um problema complexo, o da qualificação, está ligado à tecnologia. Na definição da qualificação, todos os componentes que nela intervém são resultados de lutas, tanto de classes como de gêneros. (HIRATA, 2002, p.198) 
Hirata (2002) traz também a contribuição de Cynthia Cockburn ${ }^{35}$ sobre o tema do poder masculino e de sua apropriação da tecnologia, a qual estaria na origem da relação diferencial das tecnologias de acordo com os sexos:

\begin{abstract}
Em diversos postos de trabalho, os homens se apropriaram da tecnologia enquanto conceito, desenvolveram tecnologias de produção específicas que reivindicam como direito deles, e que defendem como domínios masculinos (...). E a partir da apropriação da esfera tecnológica pelos homens há uma construção social do feminino como incompetente tecnicamente. (HIRATA, 2002, p. 199)
\end{abstract}

As diversas pesquisas empreendidas por Hirata (2002) e outras estudadas por ela, como as de Cockburn, M. Guilbert e Danièle Kergoat nessa temática levam a autora a desenvolver a tese segundo a qual "a segregação tecnológica dos homens e das mulheres se reproduz cada vez mais no tempo" (idem).

As pesquisas efetuadas por Abramo (1998) em países da América Latina têm demonstrado as contradições presentes no mundo do trabalho em face da reestruturação produtiva, tendo em vista a inserção de novas tecnologias e da divisão sexual do trabalho. Para a autora é permitido afirmar que para as mulheres, o novo modelo de flexibilização, passa pela utilização intensiva de formas precárias de emprego, tais como contratos de curta duração, tempo parcial e/ou trabalho em domicilio. Uma das formas como se manifesta esse fenômeno é a concentração da presença feminina no que ela chama de empresas "mão"36 dos novos encadeamentos produtivos, ou seja, aquelas onde predomina o trabalho instável, pouco qualificado e mal pago, em oposição às empresas "cabeça" ${ }^{37}$, na qual se concentraria o traba-

Cynthia Cockburn, The material of male power, 4 páginas distribuídas no encontro de Turim, em 1983, "Produrre e riprodurre", p. 2.

36 Nas empresas "mão", segundo Abramo (1998) predominam o trabalho desqualificado e precário e nas quais se concentram as mulheres, enquanto as empresas "cabeça", de trabalhos mais qualificados são ambientes masculinos.

37 Reportando-se a Marx, Fairclough (2008, p. 255) entende que "referir-se às pessoas em termos de 'mãos' em contextos industriais é um modo de vê-las como mercadorias úteis para produzir outras mercadorias." Isto denota a desvalorização do/da trabalhador/a quando chamado/a de "mão de obra". 
Iho mais bem qualificado, mais estável e melhor remunerado.

Em outro estudo Abramo (1997) chama a atenção para a introdução de novas tecnologias redundando em abertura de novas oportunidades e em consequências positivas para o trabalho feminino, criando novas chances de emprego qualificado, sobretudo no setor de informática. Mas, Hirata (1998) alerta que a tecnologia pode também reforçar a marginalização das mulheres e constituir um risco real no plano do emprego, sobretudo para as trabalhadoras não qualificadas.

Sobre tal aspecto, Kergoat (1984, p15) assinala que "os empregos femininos são frequentemente uma prolongação das tarefas domésticas. " $\mathrm{E}$ complementando essa ideia, para M. Guilbert ${ }^{38}$ apud Hirata (2002, p.200), a divisão do trabalho que existia previamente na família (fiação no domicílio onde as mulheres produzem o fio) e os custos relativos (baixo nível do salário feminino) explicam fundamentalmente a entrada das mulheres na indústria manufatureira, mas a tecnologia é também um dos fatores que está na origem dessa feminização, diminuindo a intensidade do esforço físico, ao simplificar o trabalho.

Porém, para Abreu (1994, p.55) a ideia largamente difundida nos anos 60 de que as novas tecnologias microeletrônicas, ao eliminar trabalhos pesados e sujos, iriam permitir uma real igualdade entre homens e mulheres no mercado de trabalho foi sendo desmentida ao longo das duas décadas seguintes, "diante da constatação irrefutável da reconstrução continuada das diferenças que mantinham o fosso entre o trabalho qualificado dos homens e o trabalho desqualificado das mulheres".

Ainda reportando-se às pesquisas de M. Guilbert, Hirata (2002, p. 200) dá indicações sobre as relações entre as técnicas e os equipamentos utilizados e a divisão sexual do trabalho:

- Há um tipo de máquinas confiadas às mulheres: as tarefas femininas são "predominantemente manuais"; as tarefas masculinas consistem em fabricar ferramentas, em montar e regular as ferramentas nas máquinas, em consertá-las; eles exercem "os ofícios da mecânica";

- As qualidades requeridas são muito diferentes: a rapidez e a 
destreza maior das mulheres é a razão de sua utilização nas cadeias de montagem e sua capacidade de executar um trabalho simples, minucioso, monótono e efetuado de maneira conscienciosa é mencionada para sua utilização nos trabalhos de controle;

- A clivagem entre tarefas masculinas e femininas é nítida: a utilização de tornos automáticos, "modernos", descarta as mulheres. Ao contrário, quando se trata de tornos comuns ou semiautomáticos, em que as operações manuais voltam a ter importância, a mão de obra feminina reaparece.

Assim, para Hirata (2002a), não se confiam máquinas complexas às mulheres e o sexo da mão de obra varia de acordo com o nível de automação e de qualificação.

Para Kergoat ${ }^{39}$ apud Hirata (2002 p, 202) "o movimento de desqualificação/superqualificação afeta em sentido inverso operários e operárias e esse fenômeno vai se acentuando no decorrer dos anos". A automação cria empregos não qualificados, em geral feminizados, tanto no terciário quando no secundário. Se os empregos não qualificados são feminilizados, isso acaba fazendo da não qualificação uma espécie de qualificação "tipicamente" feminina. "A habilidade para trabalhar com muita rapidez é uma qualificação criada, de maneira não intencional pela desqualificação".

Tendo como referência as teses de Kergoat (ob. cit.), Hirata (2002, p. 202-203), apresenta os efeitos sociais da tecnologia conforme sua utilização por uma população masculina ou feminina:

- Sobre o emprego: os empregos femininos são os mais afetados pela informatização do terciário e, nos empregos industriais, os efeitos são diferenciados de acordo com os ramos e as consequências do processo de trabalho atingido pela robotização;

- Sobre a qualificação: assiste-se a um aumento da qualificação masculina - ligados aos serviços de prestígio, à informática e a projetos. E a uma redução maciça da qualificação feminina - encarregadas de digitação, codificação, trabalhos repetitivos, monótonos, de controle etc.

- Sobre a relação com o trabalho: há duas fases nos postos de trabalho informatizados: uma fase de interesse provocado pelo sentimento se,1986, p.106. 
de maior polivalência e, uma segunda fase de "desencantamento", quando os empregados/as percebem que as tarefas são ainda mais desqualificadas, que eles não têm acesso a um novo saber, mas, ao contrário perdem seu saber antigo, do qual o computador se "apropriou".

A partir das conclusões de Kergoat (1982), nas quais:

\begin{abstract}
A tecnologia não leva mecanicamente a uma evolução do trabalho, mas, sobretudo, abre diversos campos possíveis de evolução, o que se estabelecerá em função do social. A divisão do trabalho tende a aumentar com a evolução tecnológica tanto no nível da divisão sexual do trabalho quanto no da divisão entre trabalho manual e trabalho intelectual. Assistese, de fato, a processos de superqualificação/desqualificação da força de trabalho, que aumentam com uma divisão sexual da distribuição dos postos no processo de trabalho cada vez mais solidificada. Nessa perspectiva, as próprias noções de "trabalho manual", "trabalho intelectual" devem ser redefinidas. (HIRATA, 2002, p. 203).
\end{abstract}

Hirata (2002, p.203-204) afirma a necessidade da apreciação da divisão sexual do trabalho, devida às mudanças tecnológicas recentes, em certo número de ramos e setores econômicos. Partindo do pressuposto de que não se pode estudar a divisão sexual do trabalho e o trabalho das muIheres unicamente nas indústrias de mão de obra feminina, a autora sugere que indústrias tais como a siderúrgica, a petroquímica, a de cimento ou a de vidro são lugares privilegiados de análise da divisão do trabalho de acordo com os sexos e das concepções de masculinidade e feminilidade que ali são efetivadas. Essa abordagem, segundo Hirata, permite ver como a composição sexuada da mão de obra pode passar por uma mutação, logo após mudanças tecnológicas importantes, deslocando as fronteiras do trabalho feminino e do masculino.

Em oposição a essas tendências recentes no trabalho profissional feminino nas indústrias, as mudanças no trabalho doméstico são menores e muito mais lentas. Se o forte desenvolvimento das tecnologias domésticas tendeu a facilitar essas tarefas, a divisão sexual do trabalho doméstico e a atribuição deste último às mulheres, em realidade, continuaram intactas. $A$ relação entre o trabalho doméstico e a afetividade parece estar no centro dessa permanência.

\title{
Os avanços nas tecnologias de gestão e a divisão do
}




\title{
trabalho entre os sexos
}

Segundo Abreu (1994, p. 52-53) até recentemente, o perfil do trabalhador industrial da segunda metade do século XX parecia estar definido pelas características do modelo fordista, paradigmático do sistema de produção de massa.

\begin{abstract}
Baseado na fabricação em grandes séries de bens padronizados a preços cada vez menores e utilizando maquinaria especializada, o modelo fordista de produção de massa tinha como típico o trabalhador semiqualificado que cumpre rigorosamente normas operacionais, em que a disciplina conseguida através de controle estrito, era o eixo central da qualificação requerida. (ABREU, 1994, p. 52-53)
\end{abstract}

A partir da ideia de flexibilização, inúmeros estudos ${ }^{40}$ apontam para a Lógica de Competências como uma forma de regulação das relações de trabalho, ao final da década de 1970 em resposta à crise do modelo taylorista-fordista, que tinha como regra o trabalho prescrito e a separação do trabalho de concepção e de execução. Emergindo a partir do discurso empresarial francês baseai-se na flexibilidade das relações de trabalho e de produção.

Segundo Hirata (2002) a noção de competência é oriunda do discurso empresarial nos últimos dez anos, na França, e retomada em seguida por economistas e sociólogos. É uma noção ainda bastante imprecisa e decorreu da necessidade de avaliar e classificar conhecimentos e habilidades gestadas a partir das atuais exigências de situações concretas de trabalho, associada, portanto aos novos modelos de produção e gerenciamento, e substitutiva da noção de qualificação ancorada nos postos de trabalho e das classificações profissionais que lhes eram correspondentes.

Para Dugué (1999), a referência às competências é uma resposta às insuficiências do sistema da qualificação face às novas condições. As numerosas análises do modelo da competência têm mostrado como ele responde às transformações dos sistemas de trabalho: os modos de prescrição evoluindo, recorre-se à mobilização psíquica dos trabalhadores e não mais somente aos seus conhecimentos. Além disso, com a reelaboração per- 
manente dos empregos interditando sua codificação, torna-se necessário desatrelar a negociação salarial de todo e qualquer vínculo com postos ou saberes preestabelecidos. O modelo de competência, então, responderia a este duplo problema.

As competências são definidas como "saberes em ação", ou seja, um conjunto de conhecimentos e de maneiras de ser que se combinam harmoniosamente para responder às necessidades de uma dada situação em um dado momento. Enquanto os diplomas validam saberes, as competências remetem a uma integração de saber e de comportamento que confere um

lugar preponderante ao "saber-ser" e ao investimento psicológico. Enquanto os diplomas são adquiridos de uma vez por todas, dando à noção de qualificação uma dimensão estabilizadora, a competência, por definição "inqualificável", é da ordem do conjuntural e não pode ser considerada um atributo definitivo. (STROOBANTS, 2002).

Para Zarifian (2001) o conceito de competência procura ir além do conceito de qualificação, pois, refere-se à capacidade de a pessoa assumir iniciativas, ir além das atividades prescritas, ser capaz de compreender e dominar novas situações no trabalho, ser responsável e ser reconhecido por isso. Ressalta-se também a valorização dos saberes em ação, a inteligência prática dos/as trabalhadores/as independente de títulos e diplomas; uma maior polivalência do/a trabalhador/a, que lhe permite lidar com diferentes processos e equipamentos, assumir diferentes funções e tornar-se multiqualificado/a.

Em Küenzer (2003, p.10), é possível compreender a categoria competência como,

a capacidade de agir, em situações previstas e não previstas, com rapidez e eficiência, articulando conhecimentos tácitos e científicos a experiências de vida e laborais vivenciadas ao longo das histórias de vida, vinculada à idéia de solucionar problemas, mobilizando conhecimentos de forma transdisciplinar a comportamentos e habilidades psicofísicas, e transferindoos para novas situações; supõe, portanto, a capacidade de atuar mobilizando conhecimentos. (KÜENZER, 2003, p.10)

Em seu estudo sobre a lógica de competências, Fidalgo \& Fidalgo (2005), relatam que apesar das reiteradas afirmações de diversos autores sobre as imprecisões conceituais da noção de competências, há várias convergências entre eles, tais como: a competência como capacidade de 
articulação e mobilização de saberes, conhecimentos, habilidades e atitudes; a exaltação do sentido de eficácia das competências diante dos acontecimentos e, finalmente, o movimento em direção ao processo de individualização e de competição entre os/as trabalhadores/as.

Diante das mudanças técnicas, organizacionais e econômicas ocorridas nos últimos anos, as empresas têm progressivamente substituído o modelo de "qualificação" pelo de "competências". No entanto, conforme afirmam Fleury \& Fleury (2004), no âmbito dos profissionais de gestão de recursos humanos há uma tendência da utilização do conceito de competência como algo que pode ser prescrito, medido, quantificado e avaliado e do uso de padrões baseados em conhecimentos, habilidades e atitudes que afetam o trabalho e o desempenho do/a trabalhador/a. Tal entendimento aponta para a utilização do modelo de competência como uma nova roupagem para a qualificação na gestão do trabalho humano.

Assim, os princípios do trabalho centrados na tarefa e no conjunto de tarefas referentes aos cargos continuam em pauta, sem levar em consideração a subjetividade do/a trabalhador/a. Machado (2008) esclarece que, embora as competências sejam inerentes ao ser humano, a valorização de determinado perfil de competências surgiu na reestruturação capitalista para responder ao aumento da competição das empresas no mercado, às mudanças tecnológicas, à necessidade de redução dos custos e de melhoria da qualidade dos processos produtivos e dos produtos. Para tal, acompanha esse processo a proposta de mudança na gestão do trabalho:

[...] No que se refere à gestão do trabalho, o novo marco geral orientador preconiza a sintonização das competências individuais com as competências da organização, a busca da harmonia das atuações de cada um com esse planejamento estratégico. (MACHADO, 2008, p. 288)

Desta forma, o uso da noção de competências insere-se um amplo quadro político de gestão estratégica de interesses sociais e profissionais e de renegociação quanto ao uso social do trabalho. Envolve escolhas que não são neutras no que concerne à reorganização de mercados de trabalho e de processos de trabalho, e às mudanças na divisão técnica e sexual do trabalho. Neste contexto, a divisão sexual do trabalho, apesar de ser algo antigo, permanece.

Os estudos de Pereira e Fidalgo (2007) apontam para a divisão sexual 
do trabalho como uma categoria de análise que possibilita delimitar os lugares sociais atribuídos aos homens e às mulheres, bem como identificar os valores atribuídos a eles e as regras de comportamento decorrentes destes valores no mundo do trabalho. Considerando as mudanças advindas da reestruturação produtiva e da gestão da força de trabalho pela lógica de competências, os autores constatam que as transformações ocorridas por este novo modelo foram bastante significativas para as mulheres, pois tiveram oportunidades de serem inseridas em ocupações de comando e em funções consideradas masculinas. Evidenciam que a necessidade de comprovação dos saberes é maior para as mulheres, principalmente para aquelas que ocupam funções consideradas masculinas e de maior nível hierárquico e afirmam ainda que,

\footnotetext{
[...] algumas competências socialmente atribuídas a elas estão sendo reconhecidas e valorizadas pelas empresas, tais como a capacidade de adaptar-se às mudanças e de realizar várias tarefas, de relações humanas, comunicação, mobilização e engajamento para com os objetivos da empresa e comprometimento. (PEREIRA e FIDALGO, 2007, p.160).
}

Desta forma, relatam os autores, as mulheres têm usado como estratégia o aperfeiçoamento das competências consideradas femininas para inserção em cargos de maior escalão e aquelas competências consideradas masculinas - objetividade, competitividade, autonomia etc. para ocupação de cargos socialmente atribuídos aos homens. Assim, o que a lógica de competência traz de novo em relação à divisão social de sexos é o reconhecimento, valorização e ressignificação de determinadas competências socialmente atribuídas às mulheres, aquelas adquiridas no trabalho doméstico, exercido no espaço privado.

Também Segnini (1998, p.178) revela que os espaços privados e as tarefas domésticas passam a ser um elemento qualificador, pois possibilitam à mulher desenvolver habilidades requeridas e valorizadas para a realização do trabalho flexível. No entanto, para Kergoat (1982, p.198), essa qualificação não é reconhecida como qualificação profissional, porque é criada em uma esfera diferente daquela do terreno profissional e produtivo. Forjadas no âmbito privado, nas tarefas domésticas, no trabalho reprodutivo, "(...) as qualidades exigidas das mulheres (minuciosidade, perspicácia, paciência etc.) são tidas como inatas e não adquiridas - fatos da natureza e não da cultura, aptidões e não savoir-faire". 
Pode-se inferir, a partir da assertiva de Kergoat, a hipótese de que, sendo a família o primeiro ambiente socializador na qual se dá a divisão do trabalho entre homens e mulheres, as competências das mulheres foram construídas no ambiente doméstico e levadas para o mundo do trabalho, não tendo assim um status de qualificação profissional. Porém os dados empíricos da pesquisa que originou a presente tese evidenciam uma tendência à reversão desse quadro32. Também um estudo realizado pela consultoria internacional Great Place to Work, publicado no Jornal Gazeta do Povo, em 3 de março de 2009, sinaliza que as empresas têm ganhado muito com a contratação de mulheres e, afirma ainda, que elas conseguiram um espaço maior em diferentes carreiras no mundo corporativo pelas suas "qualidades", como: empatia, paciência, habilidade em trabalhar em equipe, capacidade de delegar e negociar, entre outras.

Em se tratando das inovações tecnológicas no ambiente industrial eliminando as tarefas pesadas e a adoção de novos modelos de gestão valorizando as competências ditas femininas, Abreu (1994, p. 155) e Neves (2000, p. 243) esperavam uma maior incorporação das mulheres no mundo do trabalho em ocupações qualificadas e a eliminação da discriminação a que estão submetidas. Porém, Stancki (2003,p.59) afirma que a substituição do uso da força bruta pelo uso de equipamentos computadorizados, não necessariamente abre espaços para a atuação das mulheres nas áreas industriais, pois a ciência e a tecnologia, continuam sendo consideradas de domínio masculino.

Os estudos de Pereira \& Fidalgo (2007), no entanto, mostram a abertura de novas oportunidades de trabalho para as mulheres advindas do avanço tecnológico. Na fábrica automobilística pesquisada pelos autores, as transformações ocorridas no âmbito da gestão do trabalho foram bastante significativas para a força de trabalho feminina, proporcionando a inserção de mulheres em ocupações de comando e em ocupações consideradas masculinas. Outro fator relevante verificado pelos autores refere-se à Lógica de Competências trazendo o reconhecimento, valorização e ressignificação de determinadas competências, socialmente atribuídas às mulheres.

Também a pesquisa empreendida por Quirino (2011), em empresas mineradoras, constata que as competências "ditas femininas" têm sido consideradas como um diferencial importante na hora da contratação. Associados a estas "competências femininas", o maior nível de escolarização das mulheres e o desenvolvimento tecnológico têm garantido às mulheres 
novas oportunidades de trabalho neste segmento industrial majoritariamente masculino e em profissões inusitadas, tais como: mecânicas, soldadoras, operadoras de equipamentos pesados entre outras.

Tais fatos sinalizam mudanças na visão naturalizada dos papéis sociais atribuídos aos homens e às mulheres no mundo do trabalho produtivo.

\section{Considerações finais}

A realização do trabalho, no interior do sistema produtivo ou fora dele, acontece dividida para a realização de sua eficácia e para o maior controle capitalista. Assim, a tecnologia entra no processo produtivo também dividida em tecnologia física e de gestão. Cabe ao gestor capitalista a distribuição das tarefas e das funções, bem como seu gerenciamento à procura crescente de produtividade, e de mais-valia relativa e/ou absoluta.

Desta forma, há uma inteligência no setor de contratação e alocação do/a trabalhador/a distribuindo as responsabilidades da produção conforme a qualificação e as competências da força de trabalho, aí incluindo o reconhecimento da diferenciação de sexos, para melhor eficiência produtiva.

Ao capital interessa o avanço tecnológico para agregar mais lucro em crescimento do lucro e acumulação de riqueza desconhecendo, peculiaridades da força de trabalho, se masculina ou feminina. Interessa a ele, tão somente, o crescimento da produtividade. Para tal, todas as divisões do trabalho são favoráveis desde que a produção se efetive com incremento cada vez maior, como: a divisão técnica, a divisão internacional, a divisão sexual.

O caráter social da tecnologia fica condicionado às condições de mais-valia crescente. Tornar-se sujeito social na definição de uma identidade no mundo do trabalho capitalista, se restringe ao/a trabalhador/a que se espeIha no modo de produção vigente no sistema do capital. Então, abrem-se condições para a mulher se adentrar mais no sistema produtivo desde que ela se enquadre nas condições reais e concretas da atividade produtiva. Assim, há alguns avanços na inserção da mulher, em ramos industriais e em profissões tipicamente masculinas; o crescimento de sua formação e qualificação profissional com o aumento das matrículas em cursos superiores, mas com pequena inserção na área de Ciências Exatas e Tecnológicas, já se configurando, desde a formação profissional inicial, uma divisão sexual. 


\section{Referências}

ABRAMO, Laís A Situação da mulher no mercado de trabalho Latino Americano. In: Textos para debate internacional. Cadernos Cut, n. 11,São Paulo, 1998.

ABREU, Alice Rangel de Paula. Especialização flexível e gênero: debates atuais. In: São Paulo em Perspectiva, n. 81, ano 1, p. 52-57. Janeiro a março de 1994.

BASTOS, João Augusto S. L. A. Tecnologia \& Interação. Curitiba: CEFETPR, 1998.

CARVALHO. Marília Gomes de. (org.) Relações de Gênero e Tecnologia. Curitiba: CEFET-PR, 2003.

CORREAA. Maíra B. Tecnologia. In: CATTANI, Antonio D. (Org.) Trabalho e Tecnologia: Dicionário Crítico. Porto Alegre-RS: Editora da Universidade. Petrópolis-RJ: Vozes, 1997.

DUGUÉ, E. La Logique de la compétence: le retour du passé. In: La logique de La compétence. Revue Education Permanente. Arcueil, França, 1999, n. 140.

FARIA, José H. Tecnologia e Processo de Trabalho. Curitiba: Editora da UFPR, 1992.

FIDALGO, Fernando S. R. e FIDALGO, Nara L.R. A Lógica de Competências e a Certificação Profissional. In: ARANHA, Antônia V. S. CUNHA, Daisy M. e LAUDARES, João Bosco. Diálogos sobre Trabalho: perspectivas multidisciplinares. Campinas-SP: Papirus, 2005.

FIGUEIREDO, Vilma. Produção Social da Tecnologia. São Paulo: EPU, 1989.

FLEURY Afonso e FLEURY, Maria Tereza L. Estratégias empresariais e formação de competências: Um quebra-cabeça caleidoscópico da indústria brasileira. São Paulo: Atlas, 2004.

GALLINO, Luciano. Dicionário de Sociologia. México, DF: Siglo Veintiuno, 1995.

HIRATA, Helena. Nova Divisão Sexual do Trabalho? Um olhar voltado para a empresa e a sociedade. São Paulo: Boitempo, 2002.

KERGOAT, Danièle. Les Ouvrières. Paris: Le Sycomore, 1982.

KERGOAT, Danièle. Le sexe du travail: structures familiales et système 
productif. Paris: P.U.G., 1984.

KÜENZER, Acácia Zeneida. Competência como Práxis: os Dilemas da Relação entre Teoria e Prática na Educação dos Trabalhadores. Boletim Técnico do Senac. Rio de Janeiro. Vol. 29. Num. 1. Jan./abr./2003

LAUDARES, João Bosco. A trajetória histórica da tecnologia com base científica. Anais do $2^{\circ}$. Seminário Nacional de História da Ciência e da Tecnologia \& $7^{\circ}$. Congresso Latino Americano de História da Ciência e da Tecnologia. Salvador- BA: Sociedade Brasileira da História da Ciência. 12 a 15 nov. 2010.

MACHADO, Lucília R. de S. O "modelo de competência" e regulamentação da base nacional e a organização do ensino médio. Trabalho e Educação, Belo Horizonte. N. 4, ago-dez. 1998

NEVES, Magda de A. Reestruturação Produtiva, qualificação e relações de gênero. In: ROCHA, Maria Izabel Baltar da (org.) Trabalho e Gênero: mudanças, permanências e desafios. Campinas: ABEP, NEPO/UNICAMP e CEDEPLAR/UFMG. São Paulo: Ed. 34, 2000.

PEREIRA, Jacqueline S. F.; FIDALGO, Fernando. A gestão do trabalho e o desenvolvimento de competências segundo o sexo. In: FIDALGO, F.; OLIVEIRA, M. A. M. e FIDALGO, N. L. R. (Orgs.). Educação profissional e a lógica das competências. Petrópolis-RJ: Vozes, 2007.

PINTO, Álvaro Vieira. O Conceito de Tecnologia. Volume 1. Rio de Janeiro: Contraponto, 2005.

QUIRINO, Raquel. Mineração também é lugar de mulher! Desvendando a (nova?!) face da divisão sexual do trabalho na mineração de ferro. Tese de doutorado em Educação. Faculdade de Educação da Universidade Federal de Minas Gerais. Belo Horizonte, 2011.

ROPÉ, Francoise. e TANGUY Lucy. (Orgs.), Saberes e competências - O uso de tais noções na escola e na empresa. Campinas: Papirus, 2002.

SEGNINI, Liliana. Mulheres no trabalho bancário: difusão tecnológica, qualificação e relações de gênero. São Paulo: Universidade de São Paulo, 1998.

STROOBANTS, M. A visibilidade das competências. In: ROPÉ, F., TANGUY L. (Orgs.), Saberes e Competências: o uso de tais noções na escola e na empresa. Campinas: Papirus, 2002.

ZARIFIAN, Philipe. Objetivo competência: por uma nova lógica. São Paulo: Atlas, 2001. 